http://jmscr.igmpublication.org/home/ ISSN (e)-2347-176x ISSN (p) 2455-0450

crossref DOI: https://dx.doi.org/10.18535/jmscr/v7i11.37

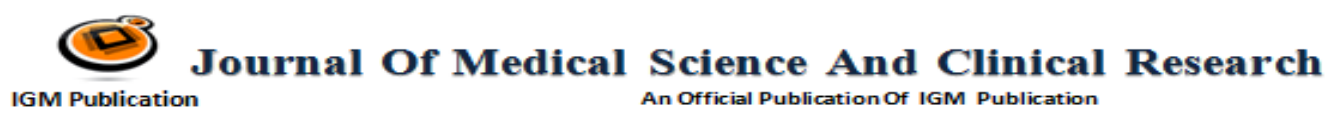

\title{
Complexities in life of a medico-Let's take the initiative to lessen the ever increasing burden
}

\author{
Author \\ Uneza Husain \\ Institute of Medical Sciences, Banaras Hindu University
}

Life of a medico is becoming difficult day by day. Parents instead of being proud, now a days are scared of sending their descendants in medical colleges as they spend major part of their life juggling with books and clinical cases. Many cases of anxiety, suicidal tendency, tension headache are seen and the number is increasing day by day.

They live a sedentary lifestyle. Lack of exercise leads to obesity and associated health hazards. Many of them suffer from non communicable diseases which could have been prevented by healthy diet, exercise and stress free lifestyle.
Perennial stress and ever increasing pressure to compete amongst medicos are beginning to take its toll and it's high time that we should incorporate simplified and easy, non hectic ways of learning for medical students in colleges.

Regular breaks, yoga classes and recreational activities, though looks irrelevant but are today's need and every effort big or small should be taken to lessen the burden amongst them. We should pledge to give them normal life, at least our future generations, not to make them work like slaves, after all they are contributing so much to the society by giving their precious and invaluable time. 